\title{
Successful treatment of an extensive retinal damage due to blunt ocular trauma
}

\author{
Ayse Gul Kocak Altintas*, Cagri Ilhan and Mehmet Citirik \\ Medical Doctor-Associated Professor, Ulucanlar Cad. No: 5906230 Altindag, Turkey
}

\begin{abstract}
Submacular hemorrhage (SMH) generally occurs associated with several conditions such as age-related macular degeneration, retinal vascular diseases, or ocular trauma. In unthreaded cases, retinal architecture and metabolic activities are damaged, hence SMH can result permanent visual loss. There are several treatment modalities of SMH including pneumatic displacement with or without tissue plasminogen activator or vitrectomy and all of them aim to reduce the photoreceptor and RPE exposure from the devastating effects of hemorrhage. The patient presenting in this case report, admitted to hospital with sudden visual loss after blunt ocular trauma. We observed SMH combined with multiple retinal tears and intraretinal hemorrhage on temporal peripheral retina. We performed peripheral laser photocoagulation on temporal retina around the retinal tears in first day of his complaint and intravitreal bevacizumab injection and pure $0.3 \mathrm{ml}$ of $100 \%$ perfluoropropane gas intravitreal injection for pneumatic displacement an hour later. After maintaining a prone position during 7 days, complete displacement of SMH was obtained. The visual acuity of patient improved to $20 / 25$ even though there were non-foveal-involving large choroidal rupture and peripheral tears associated with blunt ocular trauma. In one-year follow-up period, serious complications due to either intravitreal injection and late complications of blunt trauma including endophthalmitis, choroidal neo-vascular membrane, retinal detachment or vitreous hemorrhage was not seen. In conclusion, immediate intravitreal expansible gas injection is effective and safe in removal of traumatic $\mathrm{SMH}$.
\end{abstract}

\section{Introduction}

Ocular blunt trauma can cause massive submacular hemorrhage $(\mathrm{SMH})$ which results in suddenly deterioration of visual acuity (VA) and permanent visual loss. In unthreaded cases, hemorrhage behaviors like a barrier between the photoreceptors and retinal pigment epithelium (RPE) and it directly blocks oxygen and nutrients distribution in retinal layers [1]. Fibrin strands also produce mechanical traction on the photoreceptors and they damage retinal architecture, during the clot retraction process $[2,3]$. These time-specific mechanisms contribute to worsening in visual prognosis with increasing duration of SMH. SMH has high-risk potential that threats retinal anatomy and visual function. The most common treatment strategy is to displace of hemorrhage with expansible gas injection [3].

In this case report, we presented traumatic peripheral retinal tears and $\mathrm{SMH}$ which was completely displaced by intravitreal pure perfluoropropane gas (C3F8) injection. To prevent development of choroidal neo-vascular membrane (CNM), intravitreal bevacizumab injection combined with peripheral laser photocoagulation for treatment of retinal tears. As far as we know, our case is the first case that has best functional outcomes with the prompt treatment after severe blunt ocular trauma even with extensive retinal damage in different side of retina.

\section{Case report}

A 25-year-old boy presented the ophthalmology department with a sudden decrease of vision and a central scotoma in the left eye, one day after suffering a blunt trauma being hit in that eye with a wooden stick. Best corrected VA showed only the ability to perceive hand motion in the left eye compared to $20 / 20$ in the right eye. The intraocular pressure (IOP) was $12 \mathrm{mmHg}$ in both eyes. Assessment of the anterior segment of the left eye showed minimal laceration of the bulbar conjunctiva. Hyphema, traumatic cataract or rupture of the globe was not seen. Fundoscopy revealed subretinal hemorrhage involving the fovea and on temporal periphery a slight vitreous hemorrhage with retinal tears and intraretinal hemorrhage without retinal detachment. There were hypoflurescent areas on fundus fluorescent angiography correspond to the blockage on the hemorrhagic fields. Spectral domain optical coherence tomography (SD-OCT) (Spectralis ${ }^{\oplus}$, Heidelberg Engineering, Heidelberg, Germany) evaluation showed the presence of thick subretinal hyporeflective volume compatible with SMH, in the left eye. Figure 1 demonstrates the presenting posterior segment evaluation of the patient.

After the use of single-dose topical proparacaine $0.5 \%$ (Alcaine, Alcon Laboratories Inc., Fort Worth, TX, USA), laser photocoagulation of several lines was performed around the retinal tears to prevent retinal detachment. Then, left eye and periocular field were covered with sterile drape in operation room and iodine solution \% 5 was applied for 3 minutes on ocular surface for disinfecting. Intravitreal injection of $0.1 \mathrm{ml}$ bevacizumab was performed as an anti-vascular endothelial growth factor (anti-VEGF) and he was admitted to lay supine position for one hour to intraretinal penetration of bevacizumab. After performing the same sterilization procedure in the same day, $0.3 \mathrm{ml}$

Correspondence to: Ayse Gul Kocak Altintas, Medical Doctor-Associated Professor, Ulucanlar Cad. No: 5906230 Altindag, Ankara, Turkey, Tel: 90-3123126261; Fax: 90-312-3124827; E-mail: aysegulkaltintas@hotmail.com

Key words: submacular hemorrhage, ocular blunt trauma, pneumatic displacement Received: January 17, 2018; Accepted: February 09, 2018; Published: February 12, 2018 


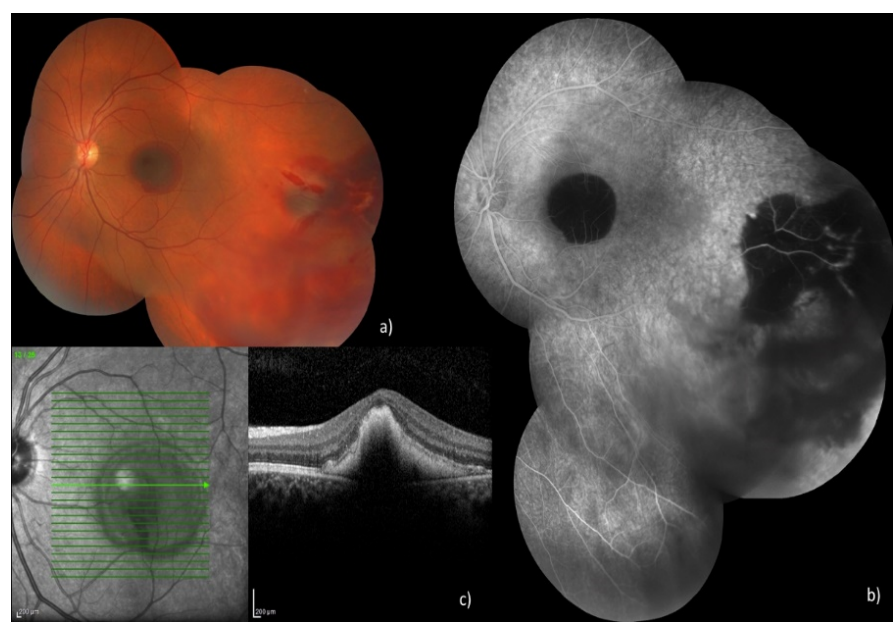

Figure 1. Submacular hemorrhage and retinal tears after blunt ocular trauma

of $100 \%$ perfluoropropane gas was injected intravitreally from $4 \mathrm{~mm}$ away the limbus on another quadrant than prior injection. Optic disc perfusion was checked with direct ophthalmoscopy immediately after each procedure. He was received combined topical ciprofloxacin (Vigamox ${ }^{\oplus}$, Alcon Laboratories Inc., Fort Worth, TX, USA) and dexamethasone $0.1 \%$ (Maxidex ${ }^{\circ}$, Alcon Laboratories Inc., Fort Worth, TX, USA) 3 times per day for 7 days. The patient was instructed to maintain a prone position in this period.

In post-injection day 1 IOP was $20 \mathrm{mmHg}$, no sign of infection was evident, and the big gas bubble was observed in the vitreous cavity. In post-injection day 7 , we instructed the patient that the prone position was no longer necessary. His VA was 20/100 and the hemorrhage started to move out of the fovea. Then, choroidal rupture was revealed on parafoveal area beneath the hemorrhage. In posterior segment evaluation post-injection month 1 , we observed that intravitreal perfluoropropane gas completely resorbed, VA improved to 20/25, minimal submacular coagulum, parafoveal pigmentation, large choroidal rupture region involved to only parafoveal region sparing to fovea, minimal subretinal arc shaped hemorrhage on superior hemisphere and laser scars around the retinal tear. SD-OCT showed distortion in retinal architecture and increase in hyperreflectivite over the choroidal rupture area and flattening of the RPE outside the distorted field. In 1-year follow-up period, VA was still remained 20/25 and we considered that choroidal rupture did not involve the fovea and intravitreal injection of bevacizumab may additional effect for resorbing the displaced SMH and prevent secondary CNM development which may involve to central fovea. Therefore, permanent visual loss was not developed. Other serious complications associated with either ocular blunt trauma or intravitreal injections including endophthalmitis or retinal detachment was not seen in this follow-up period. Figure 2 shows the final imaging of the patient (written consent was obtained from patient to use of all images in academic purposes).

\section{Discussion}

SMH generally occurs associated with several conditions including age-related macular dystrophy, retinal artery macroaneuyrsm, polipoidal choroidal vasculopathy, pathological myopia, and ocular trauma $[2,4,5]$. The functional outcomes of SMH are varying. Origin of SMH and associated ocular co-morbidities may be an important decisive factor. In our case, the origin of SMH is ocular blunt trauma and there were several ocular co-morbidities such as choroidal rupture, retinal tear, vitreous hemorrhage, conjunctival laceration. With a prompt combine treatment, we obtained both complete resolution of $\mathrm{SMH}$, and significant improvement of VA. Permanent VA lost occurs $5 \%$ cases of ocular blunt trauma due to choroidal rupture and foveainvolved cases directly cause SMH [6]. In these cases, subsequent fibrovascular degenerations restrict the recovery of VA [7]. We considered that localization of fibrovascular degenerations following choroidal rupture are responsible the permanent visual loss. With the prophylactic intravitreal bevacizumab injection, CNM secondary to choroidal rupture or vitreous hemorrhage did not occur in follow-up period and patient did not need any other treatment including another intravitreal anti-VEGF injection or vitrectomy.

The mechanism of ocular injury due to blunt trauma is increased anterior-posterior pressure to the globe. Most common posterior segment damages following blunt trauma are commotion retina, choroidal rupture, retinal tear and dialysis, traumatic macular hole and vitreous hemorrhage [8]. In our patient, more than one of these posterior segment injuries following blunt ocular trauma were present simultaneously. We need to perform multiple treatment procedure for this complicated condition to prevent the patient from permanent visual loss.

There are several treatment modalities of SMH such as intravitreal gas injection to displace the hemorrhage with or without tissue plasminogen activator (t-PA) or vitrectomy [9-11]. All treatment modalities aim to reduce the photoreceptor and RPE exposure from the toxic effects of hemorrhage. Comparing to surgical drainage, pneumatic displacement of the SMH with intravitreal expansible gas injection is relatively simple and less invasive approach [12]. Similarly, we considered that vitrectomy surgery will be aggressive first step treatment choice for 25-year-old boy who admitted to hospital in first day of his complaint. Therefore, we performed intravitreal anti-VEGF for both acceleration of absorption of hemorrhage and prevention

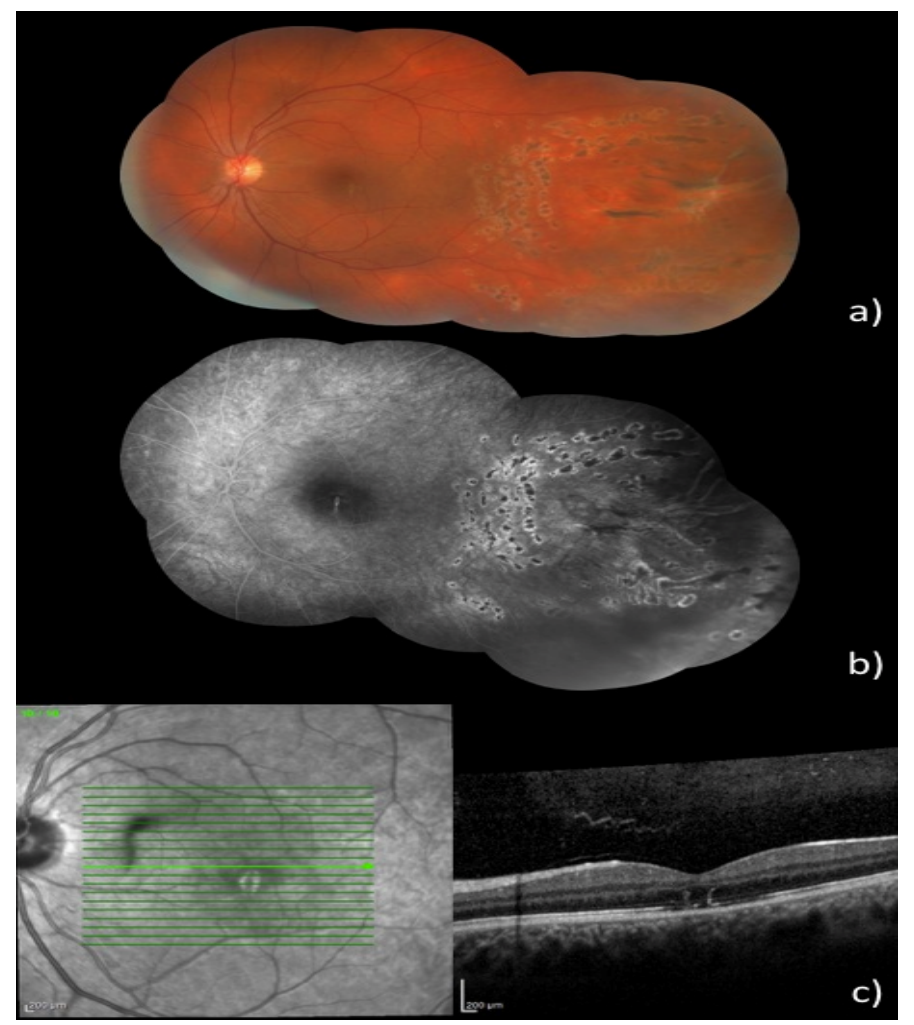

Figure 2. Resorbtion of submacular hemorrhage after treatment. 
of development of CNM combine with pneumatic displacement as a more convenient first step treatment. $0.3 \mathrm{ml} 100 \%$ perfluoropropane gas intravitreal injection was recommended in cases with low VA and thick $\mathrm{SMH}$ because of its buoyancy is more intense than sulfur hexafluoride (SF6) [13]. Buoyancy of perfluoropropane gas, moves SMH away from fovea during prone position and protects to photoreceptor and RPE. t-PA addition in intravitreal gas injection procedure can be considered to improvement the efficacy of treatment, but there are several studies that reported no significant difference in final VA among pneumatic displacement with and without t-PA groups $[9,14$, 15]. Furthermore, t-PA medication carries some potential risks such as recurrent hemorrhage in any layer of posterior segment or retinal toxicity $[16,17]$. In this regard, we treated the patient with pure $0.3 \mathrm{ml}$ $100 \%$ perfluoropropane gas intravitreal injection. If this treatment is performed with proper technique, it is effective and safe. We also did not see any of treatment related complication such as IOP spike, optic nerve non-perfusion, retinal detachment or vitreous hemorrhage.

One-week prone position is generally enough for complete displacement of SMH if there is no recurrent hemorrhage [18]. Shorter time than one week cannot provide desired effects. Insufficient positioning does not shift hemorrhage, and this is not a rare situation because maintaining of this position is difficult for patient especially those are olds, fats or have a pulmonary disease. Furthermore, prolonged stay in prone position cause psychological alterations, insomnia, neck and back pain [19]. Prone positioning during one week was effective for our patient. After this time, we observed that hemorrhage displace to superior hemisphere and macular area was clean.

In SMH cases, optimum timing of pneumatic displacement is not completely clear. An experimental study showed that severe degeneration in retinal layers occurs within 7-14 days [20]. In another study argued that irreversible retinal damage begins in first 24 hours after the subretinal blood injection [1]. These experimental studies are important because of mention the necessary of early treatment. To prevent irreversible change of macular photoreceptors, prompt displacement of the hemorrhage away from the fovea is recommended. Hence, exposure duration in foveal region decreases and movement of non-organized hemorrhagic accumulation facilitates [13]. On the contrary, Kamci et al. [21] stated that surgical removal beyond 7 days after onset of hemorrhage, associates with poor prognosis. In our case, we performed pneumatic displacement in first day of his complaints as recommended. Although final retinal architecture was far away from ideal due to the ocular co-morbidities associated with blunt trauma in parafoveal retina, his VA significantly improved.

As far as we know our case has the highest VA improvement which is nearly normal final VA, even the presence of extensive retinal damage effecting both peripheral and the central retina associated with ocular blunt trauma. In conclusion, immediate intravitreal expansible gas injection combination with intravitreal anti-VEGF injection is effective and safe in removal of traumatic SMH. With obtaining of complete macular clearance from hemorrhage, functional outcomes may improve significantly even the presence of ocular co-morbidities associated with blunt ocular trauma.

\section{References}

1. Glatt H, Machemer R (1982) Experimental subretinal hemorrhage in rabbits. Am J Ophthalmol 94: 762-773. [Crossref]

2. Hochman MA, Seery CM, Zarbin MA (1997) Pathophysiology and management of subretinal hemorrhage. Surv Ophthalmol 42: 195-213.
3. Handwerger BA, Blodi BA, Chandra SR, Olsen TW, Stevens TS (2001) Treatment of submacular hemorrhage with low-dose intravitreal tissue plasminogen activator injection and pneumatic displacement. Arch of Ophthalmol 119: 28-32. [Crossref]

4. Berrocal MH, Lewis ML, Flynn HW Jr (1996) Variations in the clinical course of submacularhemorrhage. Am J Ophthalmol 122: 486-493. [Crossref]

5. Scupola A, Coscas G, Soubrane G, Balestrazzi E (1999) Natural history of macular subretinal hemorrhage in age-related macular degeneration. Ophthalmologica 213: 97-102. [Crossref]

6. Raman SV, Desai UR, Anderson S, Samuel MA (2004) Visual prognosis in patients with traumatic choroidal rupture. Can J Ophthalmol 39: 260-266. [Crossref]

7. Ament CS, Zacks DN, Lane AM, Krzystolik M, D'Amico DJ (2006) Predictors of visual outcome and choroidal neovascular membrane formation after traumatic choroidal rupture. Arch Ophthalmol 124: 957-966. [Crossref]

8. Keles S, Ondas O, Ekinci M, Sener M.T, Erhan E (2014) Paintball related ocular trauma: paintball or painball? Med Sci Monit 20: 564-568. [Crossref]

9. Ohji M, Saito Y, Hayashi A, Lewis JM, Tano Y (1998) Pneumatic displacement of subretinal hemorrhage without tissue plasminogen activator. Arch Ophthalmol 116: 1326-1332. [Crossref]

10. Olivier S, Chow DR, Packo KH, MacCumber MW, Awh CC (2004) Subretinal recombinant tissue plasminogen activator injection and pneumatic displacement of thick submacular hemorrhage in Age-Related macular degeneration. Ophthalmology 111: 1201-1208. [Crossref]

11. Bressler NM, Bressler SB, Childs AL, Haller JA, Hawkins BS, et al. (2004) Surgery for hemorrhagic choroidal neovascular lesions of age-related macular degeneration: ophthalmic findings: SST report no. 13. Ophthalmology 111: 1993-2006. [Crossref]

12. Chen CY, Hooper C, Chiu D, Chamberlain M, Karia N, Heriot WJ (2007) Management of submacular hemorrhage with intravitreal injection of tissue plasminogen activator and expansile gas. Retina 27: 321-328. [Crossref]

13. Bae K, Cho GE, Yoon JM, Kang SW (2016) Optical Coherence Tomographic Features and Prognosis of Pneumatic Displacement for Submacular Hemorrhage. PLoS One 11: e0168474. [Crossref]

14. Fang IM, Lin YC, Yang CH, Yang CM, Chen MS (2009) Effects of intravitreal gas with or without tissue plasminogen activator on submacular haemorrhage in age-related macular degeneration. Eye (Lond) 23: 397-406. [Crossref]

15. Fujikawa M, Sawada O, Miyake T, Kakinoki M, Sawada T, et al. (2013) Comparison of pneumatic displacement for submacular hemorrhages with gas alone and gas plus tissue plasminogen activator. Retina 33: 1908-1914. [Crossref]

16. Chen SN, Yang TC, Ho CL, Kuo YH, Yip Y, et al. (2003) Retinal toxicity of intravitreal tissue plasminogen activator: case report and literature review. Ophthalmology 110: 704-708. [Crossref]

17. Kokame GT (2000) Vitreous hemorrhage after intravitreal tissue plasminogen activator (t-PA) and pneumatic displacement of submacular hemorrhage. Am J Ophthalmol 129: 546-547. [Crossref]

18. Tsuyama T, Hirose H, Hattori T (2016) Intravitreal tPA Injection and Pneumatic Displacement for Submacular Hemorrhage in a 10-Year-Old Child. Case Rep Ophthalmol Med 9809583.

19. Nakajima M, Aso H, Nakayasu K (2012) Efficacy of pneumatic displacement with 40-degree downward gaze positioning for treatment of submacular hemorrhage: report of two cases. Clin Ophthalmol 6: 1855-1858. [Crossref]

20. Toth CA, Morse LS, Hjelmeland LM, Landers MB (1991) Fibrin directs early retinal damage after experimental subretinal hemorrhage. Arch Ophthalmol 109: 723-729. [Crossref]

21. Kamei M, Tano Y, Maeno T, Ikuno Y, Mitsuda H, et al. (1996) Surgical removal of submacular hemorrhage using tissue plasminogen activator and perfluorocarbon liquid. Am J Ophthalmol 121: 267-275. [Crossref]

Copyright: (C2018 Altintas AGK. This is an open-access article distributed under the terms of the Creative Commons Attribution License, which permits unrestricted use, distribution, and reproduction in any medium, provided the original author and source are credited. 